\title{
Full scale tests of heat strengthened glass with ceramic frit
}

\author{
Matt Bergers • Kayla Natividad • \\ Stephen M. Morse - H. Scott Norville
}

Received: 24 December 2015 / Accepted: 7 May 2016 / Published online: 23 May 2016

(C) Springer International Publishing Switzerland 2016

\begin{abstract}
The authors tested five full scale samples of nominal $6 \mathrm{~mm}$ thick heat strengthened glass to failure under uniform lateral loading. One sample was clear glass, one sample had full coverage ceramic enamel frit, and the other three samples had ceramic enamel frit patterns with different percentages of coverage. In testing the samples with ceramic enamel frit applications, researchers oriented the specimens to place the ceramic enamel frit in tension under lateral loading. The authors found that the samples with ceramic enamel frit displayed considerably lower magnitudes of load resistance than did the clear heat strengthened sample. In addition, the authors noted that every fracture origin they have inspected to date from the 75 specimens with ceramic enamel frit patterns occurred underneath frit. Micrographs of fracture origins indicate that the frit may actually damage the glass surface during the heat
\end{abstract}

\footnotetext{
M. Bergers

Research and Development, Viracon, 800 Park Drive, Owatonna, MN 55060, USA

e-mail: mbergers@viracon.com

K. Natividad · S. M. Morse · H. S. Norville ( $\varangle)$

Department of Civil, Environmental, and Construction

Engineering, Texas Tech University, Lubbock, TX 79409, USA

e-mail: scott.norville@ttu.edu

K. Natividad

e-mail: kayla.natividad@ttu.edu

S. M. Morse

e-mail: Stephen.m.morse@ttu.edu
}

strengthening process. This study has significant implications for architectural glass design.

Keywords Ceramic enamel frit · Heat strengthened glass $\cdot$ Spandrel glass $\cdot$ Load resistance $\cdot$ Fracture

\section{Introduction}

Ceramic enamel frit is frequently applied in full coverage to heat treated glass lites in spandrel applications. Ceramic enamel frit also finds applications to achieve architectural and aesthetic effects. Recently, heat strengthened spandrel lites in several buildings in the US have experienced fracture resulting from thermally induced stresses. In response to the thermally induced fractures occurring in one building, three of the authors of this paper undertook a research project (Natividad et al. in review) that indicated the full coverage black ceramic enamel frit in that building reduced the load resistance of fully tempered glass and heat strengthened glass by approximately a factor of 2.0. In short, this study, accomplished with four point bending tests, indicated that fully tempered glass with the ceramic enamel frit had load resistance equivalent to that of heat strengthened glass and heat strengthened glass had load resistance equivalent to annealed glass. The research reported herein involves conducting tests on full scale rectangular specimens to determine whether the four point testing indicated a singular result peculiar to either the frit or the test method. 


\section{Background}

Glass, a brittle material, fractures when subjected to tensile stress having sufficient magnitude and duration. Glass displays a linear elastic stress-strain relationship from the inception of loading through fracture. Factors known to impact window glass strength include, but are not limited to: age, in-service weathering, load duration, lite geometry and thickness, stress conditions and surface conditions (Norville and Minor 1985). Krohn et al. (2002) reported that an applied enamel coating has a negative effect on the strength and fatigue characteristics of heat treated float glass, due to defects in the enamel. Krampe (2013) states in his dissertation that frit has long been known to reduce the strength of heat treated glass to which it is applied. His dissertation (Krampe 2013) investigates potential reasons underlying the strength reduction.

The use of ceramic enamel frit on architectural glass is a common practice allowing the inclusion of colors and patterns. Ceramic enamel frit paint is composed of minute glass particles, pigment, and a medium where the glass and pigment come together (Schmidt 2007). The ceramic enamel frit paint is applied to one side of annealed glass after it has been cut to its final size for installation. Next, the glass is heated to a temperature near its softening point and quenched to rapidly cool the outer glass fibers while the inner fibers cool slowly. During the heating process, the ceramic particles in the paint melt and fuse with the glass surface. This process produces a permanent coating over the glass surface with residual compressive surface stress (RCSS) on the exterior fibers of the glass and tension in the glass center. The quenching rate controls the magnitudes of the RCSS and the tension in the middle. To produce heat strengthened glass, the quenching rate is slower and produces RCSS ranging from 24 to $52 \mathrm{MPa}$ (ASTM C1048 2012b). To produce fully tempered glass, the quenching rate is faster and produces RCSS with a minimum value of $69 \mathrm{MPa}$ (ASTM C1048 2012b). Glass with RCSS falling between 52 and $69 \mathrm{MPa}$ is not defined (ASTM C1048 2012b). Annealed float glass with a ceramic enamel frit coating has been found to have reduced strength and fatigue resistance lower than that of standard annealed float glass. There was no difference, however, between the strength of lites enameled on the air-side versus those enameled on the tinside (Krohn et al. 2002).
Heat treatment alters two major properties of glass: its strength and the manner in which it fractures. ASTM E1300 (2012c) defines the load resistance of heat strengthened glass as twice that of annealed glass having the same geometry and the load resistance of fully tempered glass as four times that of annealed glass having the same geometry. The origins of the factors 2 and 4 for heat strengthened and fully tempered glass load resistances, respectively, are a mystery. Fracture behavior for heat strengthened and fully tempered glass differs significantly. Heat strengthened glass fracture produces relatively large shards, similar to those produced by annealed glass fracture, allowing the fracture origin location to be easily determined. Upon fracture, fully tempered glass dices into innumerable small shards, making determination of the fracture origin location difficult, if not impossible. Natividad et al. (in review) observed that while full coverage ceramic enamel frit greatly reduces the load resistance of fully tempered glass, it did not alter the fracture pattern, i.e., dicing.

\section{Test specimens}

Viracon donated the new heat strengthened glass specimens tested in this program. It shipped the specimens to testing facilities in Lubbock, TX, immediately following production. All specimens had rectangular dimensions of $965 \mathrm{~mm} \times 1930 \mathrm{~mm}$ and $6 \mathrm{~mm}$ nominal thickness. The specimens were divided into 5 samples. Table 1 summarizes the details of the samples. Sample 1 was comprised of clear specimens. Sample 2 was comprised of specimens with $40 \%$ coverage of ceramic enamel frit in a dot pattern. Sample 3 was comprised of specimens with $50 \%$ coverage of ceramic enamel frit in a line pattern. Sample 4 was comprised of specimens with $60 \%$ coverage of ceramic enamel frit in a hole pattern. Sample 5 was comprised of heat strengthened glass specimens with $100 \%$ coverage of ceramic enamel frit. Dots in Sample 2 and holes in Sample 4 have a diameter of $3 \mathrm{~mm}$. Lines in Sample 3 have a thickness of $3 \mathrm{~mm}$. The patterns for Samples 2, 3, and 4 were silk-screened onto the glass prior to heat strengthening/fusing the frit to the glass. Frit was applied to specimens in Sample 5 using a roller coat prior to heat strengthening/fusing the frit to the glass. Figure 1 shows ceramic enamel frit patterns on specimens in Samples 2, 3, and 4. Viracon designates ceramic enamel frit color as V933 Warm Grey, a bismuth based borosilicate 
Table 1 Summary of sample details

\begin{tabular}{llll}
\hline $\begin{array}{l}\text { Sample } \\
\text { number }\end{array}$ & Description & $\begin{array}{l}\text { Number of } \\
\text { specimens }\end{array}$ & $\begin{array}{l}\text { RCSS* } \\
(\mathrm{MPa})\end{array}$ \\
\hline 1 & Clear & 27 & 42.9 \\
2 & Dots & 27 & 41.1 \\
3 & Lines & 27 & 40.1 \\
4 & Holes & 26 & 42.3 \\
5 & Full-flood & 27 & 45.7 \\
\hline
\end{tabular}

frit. The frit supplier wishes to remain unnamed. The frit went to the edge of all specimens to which it was applied although no edge fractures occurred in the tests.

The first column in Table 1 gives the sample number. The second column describes the frit application. The third column gives the number of specimens tested in the sample. The fourth column gives the characteristic value of RCSS, RCSS*, for the sample, discussed below.

\section{Test procedure}

The specimens were tested in a frame consistent with ASTM E998 (2012a) which provides detailed specifications and drawings of the test chamber arrangement. In the test procedure, the test specimen, simply supported by neoprene beads set in grooves milled into structural steel members with a steel plate backing, forms the closure of an airtight chamber. During the test, air is evacuated from the chamber at a controlled rate. The difference between atmospheric pressure on the outside of the chamber and the reduced pressure inside the chamber produces the uniform lateral load acting on the test specimen. During the test procedure, described briefly below, researchers placed the air side of the clear heat strengthened glass specimens from Sample 1 in tension (toward the interior of the chamber). For the four samples with ceramic enamel frit, researchers placed the air side. i.e., the side with the ceramic enamel frit, in tension. The test procedure is described fully in other literature (Beason 1980; Abiassi 1981; Kanabolo and Norville 1984). Briefly, for each test, research personnel carried out the following steps:

(a) Remove the specimen from its crate.

(b) Place the specimen on a glass table with the edges supported to protect the ceramic enamel frit surface from damage. (c) Measure RCSS at 9 points on the specimen's tin (non-fritted) side using a Grazing Angle Surface Polarimeter (GASP).

(d) Install the specimen into the test frame.

(e) Tape the compression side of the specimen to preserve the fracture pattern.

(f) Install the exterior glazing stops.

(g) Load the specimen to fracture by evacuating air from the test frame at a controlled rate to increase the lateral load across the specimen linearly with time.

(h) Photograph the fracture pattern while the specimen is still in the test frame.

(i) Locate and remove the shards containing the fracture origin.

(j) Clean and prepare the test frame for the next specimen.

Figure 2a shows a fracture pattern for a specimen from Sample 2. The green arrow indicates the location of the fracture origin near the upper right corner of the fracture pattern. Figure $2 b$ shows a close view of the shards containing the fracture origin which occurred underneath a ceramic frit dot.

During loading, research personnel used transducers to record the pressure inside the space behind the glass thus establishing the lateral load-time history. They used a data acquisition system to record the pressure-time history, collecting measurements at a rate of $25 \mathrm{~Hz}$. They also measured and recorded center-ofglass deflection using a linear variable deflection transducer. They used deflection data as a first level check of the analysis program. Figure 3 shows a load timehistory for Specimen 5 from Sample 1. The load-time history represents the difference between atmospheric pressure outside the chamber and the reduced pressure as researcher personnel evacuate air from the test chamber.

The authors note that even though the lateral load varies more-or-less linearly with time, the maximum principal tensile stress at the fracture origin, depending on its location, in general does not. In addition, the location of the fracture origin is, in general, different on each test specimen. After fracture, research personnel located the fracture origin, noted its position relative to the lower left corner of the specimen and removed it for further study.

The authors used a non-linear finite difference analysis program (Vallabhan and Wang 1981) to determine 
Fig. 1 Frit pattern on Samples 2, 3, and 4

Fig. 2 a Fracture pattern for Specimen 1 from Sample 2 (dots pattern). b Shards containing fracture origin in Specimen 1 from Sample 2

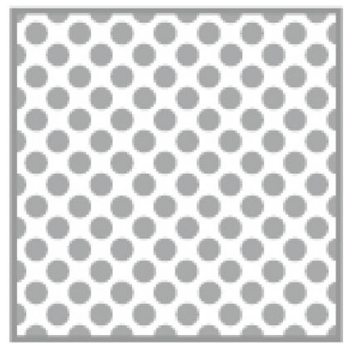

Sample 2: Dots

Dot Diameter: $3 \mathrm{~mm}$ $40 \%$ Coverage

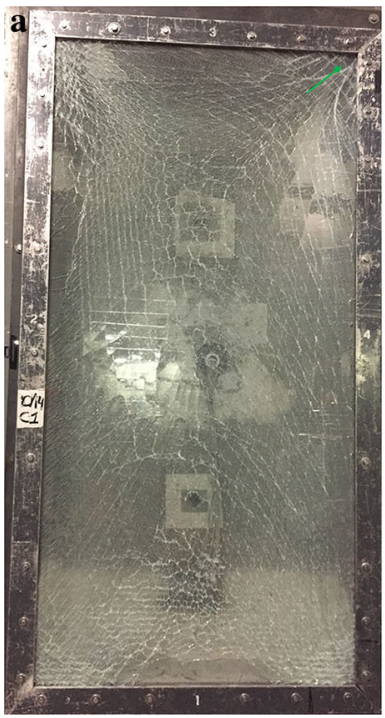

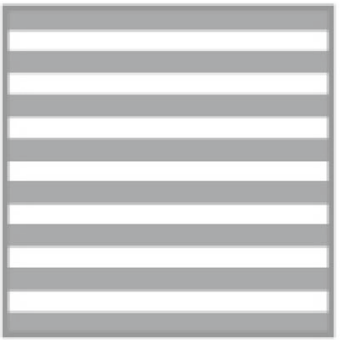

Sample 3: Lines

Line Width: $3 \mathrm{~mm}$ $50 \%$ Coverage

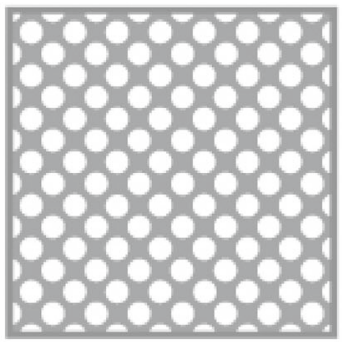

Sample 4: Holes

Hole Diameter: $3 \mathrm{~mm}$ $60 \%$ Coverage

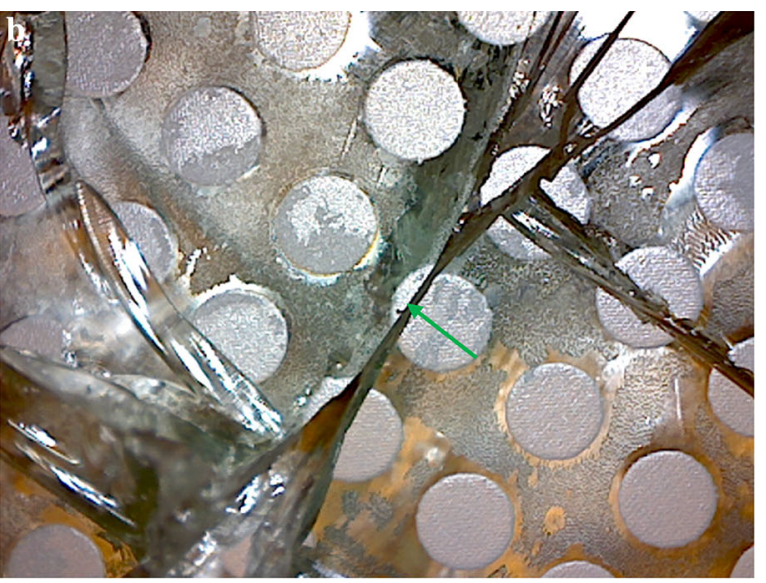

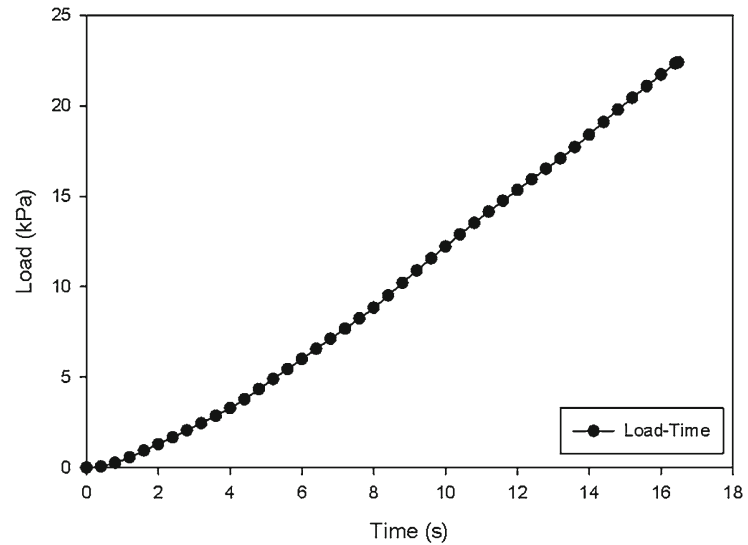

Fig. 3 Load-time history for Specimen 5 from Sample 1

maximum principal tensile stress as a function of load at the fracture origin location for each specimen. This non-linear finite difference program found extensive use in developing monolithic glass non-factored load charts in ASTM E1300 (2012c) In the tests reported herein the fracture origins tended to be located near a corner where the stress-load variation and, hence, the stress-time variation is nearly linear. Figure 4 shows a plot of maximum principal tensile stress versus time at the fracture origin location for Specimen 5 from Sample 1 corresponding to the load-time history in Fig. 3. Figure 5 shows a plot of maximum-principal tensile stress at the fracture origin location versus load for Specimen 5 from Sample 1.

\section{Data analyses}

The authors use 3-s equivalent failure loads $\left(\mathrm{P}_{3}\right)$ to represent the strengths of the specimens. The 3-s equivalent failure load is the constant magnitude of uniform 
lateral load that would lead to fracture when applied to a lite over a $3 \mathrm{~s}$ duration. They chose this time duration because ASTM E1300 (2012c) defines glass lite load resistance in terms of 3-s duration uniform lateral loadings. A comparison of the magnitudes of the $\mathrm{P}_{3}$ values, therefore, provides a comparison of the strengths of the samples consistent with ASTM E1300 (2012c).

They used the integral:

$\sigma_{3}=\left[\frac{\int_{0}^{\mathrm{t}_{\mathrm{f}}}\left[\sigma(\mathrm{t})-\mathrm{RCSS}^{*}\right]^{\mathrm{n}}}{3 \mathrm{~s}}\right]^{1 / \mathrm{n}}$

to establish the $3 \mathrm{~s}$ equivalent fracture stress for each specimen. In the above integral, $t_{f}$ denotes the time of fracture in seconds after the inception of loading, $\sigma(t)$ denotes the maximum principal tensile stress at

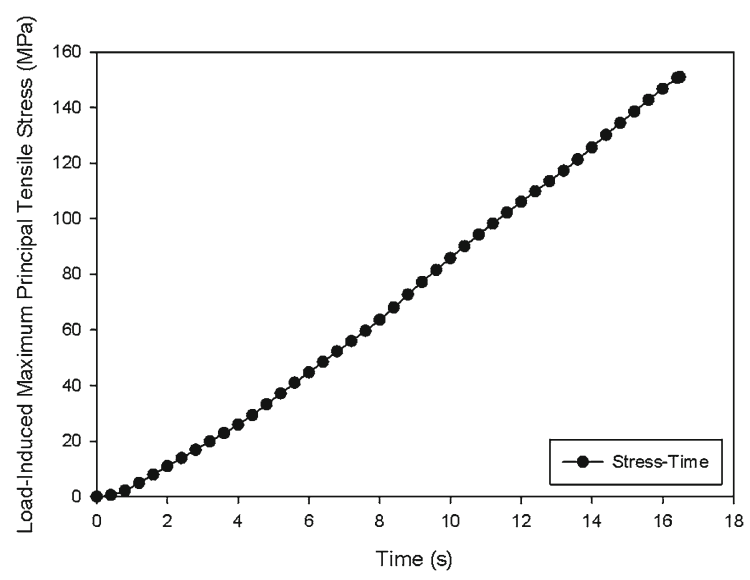

Fig. 4 Load-induced maximum principal tensile stress versus time at the fracture origin location for Specimen 5 from Sample 1

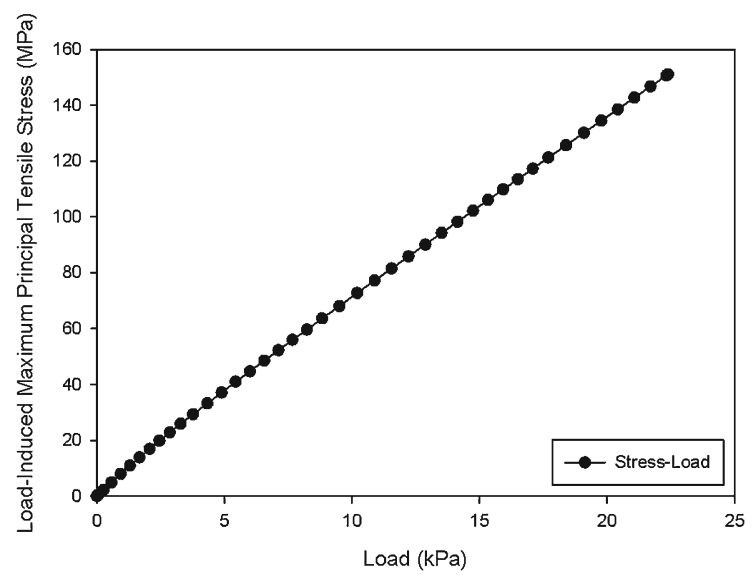

Fig. 5 Load-induced maximum principal tensile stress versus load at the fracture origin location for Specimen 5 from Sample 1 the fracture origin at time $\mathrm{t}, \mathrm{n}$ denotes the static fatigue constant for glass, and RCSS* denotes the magnitude a characteristic minimum RCSS measured in each sample. As stated above, research personnel made 9 measurements of RCSS on each specimen. They then averaged the 9 RCSS values for each specimen. The characteristic minimum value of RCSS for a sample is the lowest average for all the specimens in each sample. The authors used $n=16$ for the static fatigue constant. For times when $\sigma(\mathrm{t})<\mathrm{RCSS}^{*}$, the integrand is taken as 0 as indicated in Fig. 5. Table 1 above indicates the values of RCSS* for the specimens for each sample.

Figure 6 illustrates $\left(\sigma_{\max }-\right.$ RCSS$\left.^{*}\right)$ versus load for the Specimen 5 from Sample 1 corresponding to Figs. 3, 4 , and 5. For each specimen, they entered vertical axis of the specimen's graph similar to that Fig. 6 with the value of $\left(\sigma_{3}-\mathrm{RCSS}^{*}\right)$ projected a horizontal line to intersect the curve. They then projected a vertical line downward from the intersection. The intersection of the vertical line with the abscissa occurs at the value $\mathrm{P}_{3}$ for that specimen. Note that for the region where $\left(\sigma_{\max }-\mathrm{RCSS}^{*}\right)$ is negative the value was set to zero, both in the procedure in Fig. 6 and well as in evaluating the integral in Eq. 1.

Tables 2, 3, 4, 5 and 6 present failure and 3-s equivalent properties for all specimens in each sample. In each table, the first column gives the specimen numbers. The second and third columns give the $\mathrm{x}$ and $\mathrm{y}$ coordinates, respectively, of the fracture origin measured from the bottom left corner of the specimen with the $\mathrm{x}$-direction oriented parallel to the short edge. The fourth column presents the maximum principle tensile stress at fracture origin when fracture occurred. The fifth and sixth columns give the 3 -s equivalent stress

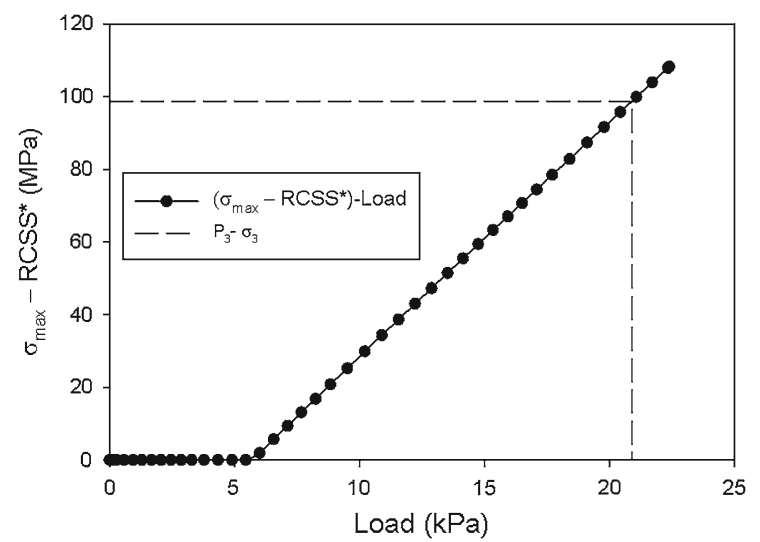

Fig. 6 Determining $\mathrm{P}_{3}$ for Specimen 5 from Sample 1 
Table 2 Sample 1 (clear) fracture origin properties

\begin{tabular}{|c|c|c|c|c|c|}
\hline \multirow[t]{2}{*}{ Specimen } & \multicolumn{2}{|c|}{$\begin{array}{l}\text { Location of fracture } \\
\text { origin }\end{array}$} & \multirow[t]{2}{*}{$\begin{array}{l}\sigma_{\max } \text { at fracture } \\
\text { origin }(\mathrm{MPa})\end{array}$} & \multirow[t]{2}{*}{$\sigma_{3}(\mathrm{MPa})$} & \multirow[t]{2}{*}{$\mathrm{P}_{3}(\mathrm{kPa})$} \\
\hline & $\mathrm{x}(\mathrm{mm})$ & $\mathrm{y}(\mathrm{mm})$ & & & \\
\hline 1 & 25 & 25 & 100.7 & 96.3 & 20.0 \\
\hline 2 & 108 & 44 & 70.5 & 65.5 & 19.5 \\
\hline 3 & 946 & 1892 & 116.1 & 109.5 & 22.4 \\
\hline 4 & 933 & 32 & 109.8 & 103.0 & 21.5 \\
\hline 5 & 916 & 5 & 106.3 & 97.7 & 20.4 \\
\hline 6 & 3 & 44 & 116.3 & 115.5 & 22.9 \\
\hline 7 & 959 & 1930 & 70.7 & 62.8 & 15.5 \\
\hline 8 & 959 & 1889 & 101.2 & 97.8 & 20.2 \\
\hline 9 & 38 & 1927 & 123.5 & 119.4 & 23.6 \\
\hline 10 & 964 & 1889 & 109.8 & 102.6 & 20.8 \\
\hline 11 & 962 & 1895 & 111.8 & 102.1 & 20.9 \\
\hline 12 & 962 & 1902 & 95.8 & 87.1 & 18.7 \\
\hline 13 & 51 & 1927 & 86.3 & 79.1 & 17.5 \\
\hline 14 & 10 & 83 & 64.6 & 62.4 & 16.2 \\
\hline 15 & 962 & 1886 & 81.9 & 84.4 & 18.1 \\
\hline 16 & 43 & 1927 & 96.1 & 99.5 & 20.4 \\
\hline 17 & 44 & 1927 & 101.6 & 113.6 & 22.6 \\
\hline 18 & 149 & 1772 & 95.0 & 96.3 & 22.0 \\
\hline 19 & 965 & 1911 & 92.9 & 99.9 & 20.9 \\
\hline 20 & 27 & 1919 & 102.7 & 99.5 & 20.6 \\
\hline 21 & 962 & 1891 & 109.9 & 111.9 & 22.3 \\
\hline 22 & 11 & 99 & 67.7 & 70.0 & 19.5 \\
\hline 23 & 102 & 114 & 75.4 & 73.9 & 18.6 \\
\hline 24 & 22 & 0 & 129.2 & 132.5 & 25.8 \\
\hline 25 & 876 & 1905 & 69.4 & 68.6 & 18.8 \\
\hline 26 & 94 & 1919 & 91.3 & 95.2 & 25.6 \\
\hline Average & - & - & 94.5 & 92.3 & 20.3 \\
\hline
\end{tabular}

$\left(\sigma_{3}\right)$, and $3 \mathrm{~s}$ equivalent failure load $\left(\mathrm{P}_{3}\right)$ values, respectively, for each sample.

Krall et al. (1981) presents an empirical methodolgy to predict the location of maximum tensile stress as a function of applied lateral load, glass lite aspect ratio, and glass lite thickness. According to their methodology, the location of maximum principal tensile stress moves from the center of the glass towards the corners as load increases. Figure 7 shows a stress contour plot for Specimen 18 from Sample 5 at the failure load. This specimen fractured at the lowest load and, hence, had the lowest maximum principal tensile stress at its fracture origin of all specimens tested. The the maximum principal tensile stresses occur in proximity to the corners of the lite. In Fig. 7, the largest value of max- imum principal tenile stress, which occurs near each corner, is $20.2 \mathrm{MPa}$ while the maximum principal tensile stress stress at the glass lite's center was 16.3 MPa. It can be inferred that the maximum principal tensile stress would be located near the corners for all other specimens tested in this study that fractured at higher loads than Specimen 18 from Sample 5.

In Table 7, the first column gives the sample number. The second column presents the largest value of $\mathrm{P}_{3}$. The third column presents the smallest value of $\mathrm{P}_{3}$. The fourth column presents the average value of $\mathrm{P}_{3}$. The fifth column presents the standard deviation of $\mathrm{P}_{3}$ values for each sample. The sixth column presents the coefficient of variation of $\mathrm{P}_{3}$. The seventh column presents the reduction in the mean value of $\mathrm{P}_{3}$ 
Table 3 Sample 2 (dots) fracture origin properties

\begin{tabular}{|c|c|c|c|c|c|}
\hline Specimen & \multicolumn{2}{|c|}{$\begin{array}{l}\text { Location of fracture } \\
\text { origin }\end{array}$} & $\begin{array}{l}\sigma_{\max } \text { at fracture } \\
\text { origin }(\mathrm{MPa})\end{array}$ & $\sigma_{3}(\mathrm{MPa})$ & $\mathrm{P}_{3}(\mathrm{kPa})$ \\
\hline 1 & 905 & 1916 & 67.9 & 62.5 & 15.1 \\
\hline 2 & 818 & 1724 & 53.3 & 48.2 & 13.5 \\
\hline 3 & 946 & 1897 & 65.6 & 60.8 & 14.3 \\
\hline 4 & 937 & 1867 & 47.7 & 42.5 & 12.0 \\
\hline 5 & 953 & 1886 & 64.4 & 57.4 & 13.8 \\
\hline 6 & 946 & 64 & 54.5 & 49.9 & 13.1 \\
\hline 7 & 949 & 1892 & 58.4 & 51.9 & 12.9 \\
\hline 8 & 924 & 86 & 49.8 & 44.7 & 13.2 \\
\hline 9 & 960 & 1876 & 51.3 & 46.0 & 12.1 \\
\hline 10 & 949 & 64 & 67.6 & 63.5 & 15.3 \\
\hline 11 & 953 & 1880 & 50.2 & 47.6 & 12.4 \\
\hline 12 & 943 & 1873 & 50.8 & 52.3 & 13.4 \\
\hline 13 & 921 & 22 & 60.0 & 57.7 & 13.9 \\
\hline 14 & 959 & 1877 & 62.3 & 60.3 & 14.4 \\
\hline 15 & 67 & 19 & 60.0 & 58.3 & 14.7 \\
\hline 16 & 89 & 11 & 57.4 & 57.2 & 15.7 \\
\hline 17 & 953 & 1883 & 64.2 & 62.4 & 14.6 \\
\hline 18 & 67 & 6 & 48.9 & 47.4 & 12.6 \\
\hline 19 & 808 & 1783 & 50.3 & 49.4 & 14.0 \\
\hline 20 & 949 & 79 & 63.8 & 61.9 & 15.8 \\
\hline 21 & 954 & 1867 & 65.3 & 64.5 & 15.3 \\
\hline 22 & 905 & 1924 & 62.4 & 61.1 & 14.7 \\
\hline 23 & 892 & 54 & 57.0 & 56.4 & 15.1 \\
\hline 24 & 829 & 176 & 57.9 & 58.4 & 15.2 \\
\hline 25 & 945 & 1873 & 61.3 & 61.1 & 14.8 \\
\hline 26 & 770 & 1773 & 50.9 & 49.9 & 14.8 \\
\hline 27 & 940 & 1891 & 49.9 & 48.1 & 12.4 \\
\hline Average & - & - & 57.5 & 54.9 & 14.0 \\
\hline
\end{tabular}

for Samples 2-5 from that of Sample 1. This table indicates that as the percentage of ceramic enamel frit coverage increases the mean $3 \mathrm{~s}$ equivalent failure load decreases. In addition, although no clear trend appears with respect to percentage of ceramic enamel frit coverage in Samples 2, 3, and 4, the coefficients of variation for the samples with ceramic enamel frit are approximately $50 \%$ that of the coefficient of variation for the clear sample.

After computing values of $\mathrm{P}_{3}$ for all specimens, the authors fit Weibull (1939) distributions to the data for each sample in terms of the surface flaw parameters, m \& k, i.e., the Weibull parameters (Brown 1974). This is the method that was used to establish weathered glass strength that serves as the basis for ASTM E1300 (2012c). The surface flaw parameters allow determination of probability of breakage for lites of other sizes (Beason 1980; Norville and Minor 1985). The cumulative probability of breakage, $\mathrm{P}_{\mathrm{f}}$, is represented as,

$P_{f}=1-\exp (B)$

where B represents a risk function which depends on lite size, lite thickness, lite aspect ratio, stress distribution across the lite surface, and surface flaw parameters.

Figure 8 displays plots of the normalized experimental distributions of $\mathrm{P}_{3}$ values for all samples with best fit lines. The authors used $\mathrm{i} /(\mathrm{N}+1)$ to assign the prob- 
Table 4 Sample 3 (lines) fracture origin properties

\begin{tabular}{|c|c|c|c|c|c|}
\hline Specimen & \multicolumn{2}{|c|}{$\begin{array}{l}\text { Location of fracture } \\
\text { origin }\end{array}$} & $\begin{array}{l}\sigma_{\max } \text { at fracture } \\
\text { origin }(\mathrm{MPa})\end{array}$ & $\sigma_{3}(\mathrm{MPa})$ & $\mathrm{P}_{3}(\mathrm{kPa})$ \\
\hline 1 & 13 & 1880 & 61.8 & 57.4 & 13.8 \\
\hline 2 & 946 & 1897 & 66.4 & 60.2 & 14.0 \\
\hline 3 & 946 & 1892 & 67.3 & 60.4 & 14.1 \\
\hline 4 & 60 & 10 & 62.9 & 57.1 & 13.9 \\
\hline 5 & 953 & 1892 & 70.9 & 66.5 & 15.0 \\
\hline 6 & 959 & 1894 & 65.0 & 57.8 & 13.7 \\
\hline 7 & 56 & 6 & 60.0 & 53.7 & 13.2 \\
\hline 8 & 953 & 1892 & 62.2 & 56.2 & 13.5 \\
\hline 9 & 44 & 13 & 62.3 & 56.2 & 13.5 \\
\hline 10 & 946 & 1892 & 68.2 & 60.9 & 14.2 \\
\hline 11 & 68 & 19 & 56.9 & 51.5 & 13.4 \\
\hline 12 & 953 & 1900 & 60.9 & 54.3 & 13.2 \\
\hline 13 & 953 & 1892 & 58.1 & 51.3 & 12.7 \\
\hline 14 & 959 & 49 & 68.5 & 61.5 & 14.3 \\
\hline 15 & 956 & 1896 & 60.8 & 55.1 & 13.3 \\
\hline 16 & 937 & 1883 & 68.5 & 62.4 & 14.7 \\
\hline 17 & 895 & 25 & 64.1 & 58.5 & 14.9 \\
\hline 18 & 35 & 16 & 71.2 & 64.1 & 14.7 \\
\hline 19 & 35 & 6 & 60.6 & 54.6 & 13.2 \\
\hline 20 & 946 & 1905 & 67.2 & 62.3 & 14.3 \\
\hline 21 & 44 & 13 & 55.7 & 51.0 & 12.7 \\
\hline 22 & 949 & 1899 & 58.4 & 57.4 & 13.6 \\
\hline 23 & 953 & 1899 & 56.3 & 55.5 & 13.4 \\
\hline 24 & 946 & 64 & 52.2 & 50.7 & 13.0 \\
\hline 25 & 959 & 1883 & 45.1 & 44.3 & 11.7 \\
\hline 26 & 956 & 57 & 36.1 & 35.9 & 13.7 \\
\hline 27 & 57 & 51 & 44.7 & 42.9 & 12.1 \\
\hline Average & - & - & 60.5 & 55.5 & 13.6 \\
\hline
\end{tabular}

ability of breakage to the ith specimen in a given sample where i ranges from 1 to $\mathrm{N}$. $\mathrm{N}$ denotes the numbers of specimens in a sample. The index parameter $\mathrm{i}$ ranges from 1 to $\mathrm{N}$ with $\mathrm{i}=1$ denoting the specimen with the smallest value of $\mathrm{P}_{3}$ and $\mathrm{i}=\mathrm{N}$ denoting the largest value.

Figure 9 shows the Weibull cumulative distribution functions for the five samples found Fig. 8. The authors verified the goodness of fit comparing an AndersonDarling test (Pettitt 1976) and Kolmogorov-Smirnov test (Justel et al. 1997) at the $\alpha=0.05$ significance level. Table 8 gives the values of the surface flaw parameters, $\mathrm{m}$ and $\mathrm{k}$. The authors note that while the para- meter $\mathrm{m}$ is dimensionless the parameter $\mathrm{k}$ has dimensions of $\left\{\left[\right.\right.$ meter $\left.^{(2 \mathrm{~m}-2)}\right]\left[\right.$ Newton $\left.\left.{ }^{(-\mathrm{m})}\right]\right\}$.

The cumulative distribution functions indicate no clear trend in the mean values of $\mathrm{P}_{3}$ as the percent coverage of ceramic enamel frit increases for patterned frits. The cumulative distribution function of $\mathrm{P}_{3}$ for Sample 5 with full coverage ceramic enamel frit falls far to the left of the cumulative distribution functions of $\mathrm{P}_{3}$ for the samples with ceramic enamel frit patterns. And, of course, the cumulative distribution function of $\mathrm{P}_{3}$ for the clear heat strengthened glass sample, the sample with no ceramic enamel frit falls to the right. 
Table 5 Sample 4 (holes) fracture origin properties

\begin{tabular}{|c|c|c|c|c|c|}
\hline \multirow[t]{2}{*}{ Specimen } & \multicolumn{2}{|c|}{$\begin{array}{l}\text { Location of fracture } \\
\text { origin }\end{array}$} & \multirow[t]{2}{*}{$\begin{array}{l}\sigma_{\max } \text { at fracture } \\
\text { origin }(\mathrm{MPa})\end{array}$} & \multirow[t]{2}{*}{$\sigma_{3}(\mathrm{MPa})$} & \multirow[t]{2}{*}{$\mathrm{P}_{3}(\mathrm{kPa})$} \\
\hline & $\mathrm{x}(\mathrm{mm})$ & $\mathrm{y}(\mathrm{mm})$ & & & \\
\hline 1 & 914 & 19 & 60.3 & 55.8 & 14.0 \\
\hline 2 & 59 & 19 & 66.9 & 62.4 & 15.3 \\
\hline 3 & 11 & 1872 & 54.7 & 51.7 & 13.3 \\
\hline 4 & 946 & 1880 & 63.6 & 56.2 & 14.0 \\
\hline 5 & 960 & 1886 & 55.8 & 50.8 & 12.9 \\
\hline 6 & 927 & 70 & 44.8 & 40.1 & 12.1 \\
\hline 7 & 57 & 1899 & 57.9 & 51.3 & 13.6 \\
\hline 8 & 956 & 54 & 49.8 & 43.5 & 12.0 \\
\hline 9 & 67 & 16 & 57.7 & 52.3 & 13.8 \\
\hline 10 & 16 & 60 & 53.3 & 49.8 & 13.1 \\
\hline 11 & 953 & 1880 & 56.6 & 49.5 & 12.9 \\
\hline 12 & 64 & 21 & 55.3 & 49.6 & 13.4 \\
\hline 13 & 959 & 1899 & 50.2 & 44.0 & 12.0 \\
\hline 14 & 957 & 1887 & 58.1 & 51.3 & 13.0 \\
\hline 15 & 43 & 19 & 54.4 & 48.8 & 12.7 \\
\hline 16 & 54 & 13 & 52.0 & 45.8 & 12.4 \\
\hline 17 & 948 & 1883 & 56.7 & 51.1 & 13.1 \\
\hline 18 & 949 & 1892 & 57.1 & 55.0 & 13.6 \\
\hline 19 & 959 & 1897 & 53.8 & 52.9 & 13.3 \\
\hline 20 & 956 & 1886 & 51.0 & 47.8 & 12.5 \\
\hline 21 & 954 & 1867 & 54.6 & 53.7 & 13.7 \\
\hline 22 & 75 & 51 & 46.8 & 46.1 & 13.5 \\
\hline 23 & 935 & 1877 & 56.5 & 53.4 & 13.8 \\
\hline 24 & 70 & 13 & 51.8 & 52.9 & 14.0 \\
\hline 25 & 819 & 1784 & 54.8 & 53.7 & 14.8 \\
\hline 26 & 845 & 103 & 33.4 & 31.6 & 11.6 \\
\hline Average & - & - & 54.2 & 50.0 & 13.2 \\
\hline
\end{tabular}

In the US, lateral load resistance design values are associated with a probability of breakage less than or equal to 8 lites per 1000 at the first occurrence of the design loading ASTM E1300 (2012c). Figure 10 shows an enlarged view of the cumulative distribution functions in the region where $\mathrm{P}_{\mathrm{f}} \leq 0.01$.

In Fig. 11, the horizontal line indicates $P_{f}=0.008$. Table 9 gives values of $\mathrm{P}_{3}$ and the percentage reductions in $\mathrm{P}_{3}$ for the samples with ceramic enamel frit from the value for clear glass at the level $\mathrm{P}_{\mathrm{f}}=0.008$.

The first column of Table 9 gives the sample number. The second column gives the values of $\mathrm{P}_{3}$ for which $\mathrm{P}_{\mathrm{f}}=0.008$. The third column gives the percentage reduction of $\mathrm{P}_{3}$ for each sample from that of the clear heat strengthened glass sample. At the level $\mathrm{P}_{\mathrm{f}}=$
0.008 , the samples with partial coverage of ceramic enamel frit have 3-s duration load resistance approximately $80-85 \%$ that of the clear heat strengthened glass sample. The sample with full coverage ceramic enamel frit has 3-s duration load resistance that is approximately $63 \%$ that of the clear heat strengthened glass sample. The authors note that using the surface parameters on glass lites of different geometry would lead to slight variations in the absolute strength reduction.

\section{Observations concerning fracture origins}

At the time of writing, the authors are examining the fracture origins from each sample. At this point, every 
Table 6 Sample 5 (full flood) fracture origin properties

\begin{tabular}{|c|c|c|c|c|c|}
\hline Specimen & $\begin{array}{l}\begin{array}{l}\text { Location } \\
\text { origin }\end{array} \\
\mathrm{x}(\mathrm{mm})\end{array}$ & $\begin{array}{l}\text { fracture } \\
\mathrm{y}(\mathrm{mm})\end{array}$ & $\begin{array}{l}\sigma_{\max } \text { at fracture } \\
\text { origin }(\mathrm{MPa})\end{array}$ & $\sigma_{3}(\mathrm{MPa})$ & $\mathrm{P}_{3}(\mathrm{kPa})$ \\
\hline 1 & 60 & 6 & 35.5 & 31.5 & 10.8 \\
\hline 2 & 54 & 6 & 33.5 & 28.9 & 10.3 \\
\hline 3 & 25 & 1854 & 38.3 & 33.1 & 11.5 \\
\hline 4 & 946 & 1870 & 24.6 & 21.5 & 9.2 \\
\hline 5 & 921 & 17 & 33.3 & 28.9 & 10.2 \\
\hline 6 & 953 & 38 & 28.1 & 24.4 & 9.5 \\
\hline 7 & 916 & 22 & 37.5 & 32.9 & 10.9 \\
\hline 8 & 927 & 48 & 32.5 & 29.0 & 10.4 \\
\hline 9 & 956 & 1873 & 34.5 & 30.3 & 10.5 \\
\hline 10 & 13 & 1873 & 31.4 & 27.0 & 10.0 \\
\hline 11 & 959 & 30 & 21.9 & 19.1 & 8.8 \\
\hline 12 & 943 & 1889 & 30.4 & 26.5 & 9.8 \\
\hline 13 & 937 & 1883 & 36.2 & 31.4 & 10.6 \\
\hline 14 & 943 & 1883 & 32.8 & 33.6 & 10.9 \\
\hline 15 & 48 & 32 & 35.4 & 33.2 & 11.0 \\
\hline 16 & 49 & 19 & 36.5 & 33.6 & 11.0 \\
\hline 17 & 64 & 60 & 25.1 & 23.7 & 10.0 \\
\hline 18 & 41 & 6 & 21.7 & 20.2 & 8.9 \\
\hline 19 & 56 & 56 & 29.9 & 28.2 & 10.6 \\
\hline 20 & 776 & 268 & 33.5 & 31.5 & 11.5 \\
\hline 21 & 908 & 1907 & 38.3 & 36.9 & 11.7 \\
\hline 22 & 37 & 1919 & 29.5 & 27.9 & 10.1 \\
\hline 23 & 940 & 1905 & 35.9 & 34.6 & 11.0 \\
\hline 24 & 940 & 1915 & 36.0 & 34.4 & 11.0 \\
\hline 25 & 953 & 1873 & 39.5 & 37.7 & 11.6 \\
\hline 26 & 41 & 1877 & 35.0 & 33.7 & 11.2 \\
\hline 27 & 60 & 6 & 27.0 & 25.9 & 9.9 \\
\hline Average & - & - & 32.4 & 29.6 & 10.5 \\
\hline
\end{tabular}

fracture origin examined from the specimens with partial coverage was located under the ceramic enamel frit. In other words, for Samples 2, 3, and 4, no specimen so far has had a fracture that originated in an area of clear glass.

Figure 11 shows the shards in proximity to the fracture origin looking at the frit surface for Specimen 2 from Sample 2, the sample with $40 \%$ coverage of ceramic enamel frit in a dot pattern. The red arrow in Fig. 11 indicates the location of the fracture origin. Figure 12 shows the micrograph of the fracture origin in Fig. 11. The scale on the micrograph indicates the degree of magnification. The fracture origin is oriented so that the glass is on top and the ceramic enamel frit is on the bottom in the micrograph. The authors believe the ceramic enamel frit has penetrated the glass surface at this fracture origin, as indicated by the upward bulge indicated by another red arrow.

Figure 13 shows the shards in proximity to the fracture origin looking at the frit surface for Specimen 5 from Sample 4, the sample with $60 \%$ coverage of ceramic enamel frit in the hole pattern. The arrow in Fig. 13 indicates the location of the fracture origin. Figure 14 shows a micrograph of the fracture mirror of the specimen shown in Fig. 13. This view looks at the fracture mirror at an angle with the ceramic enamel frit above the glass. The fracture origin is in the center of the fracture mirror under the ceramic enamel frit. The 
Fig. 7 Contour plot of Specimen 18 in Sample 5

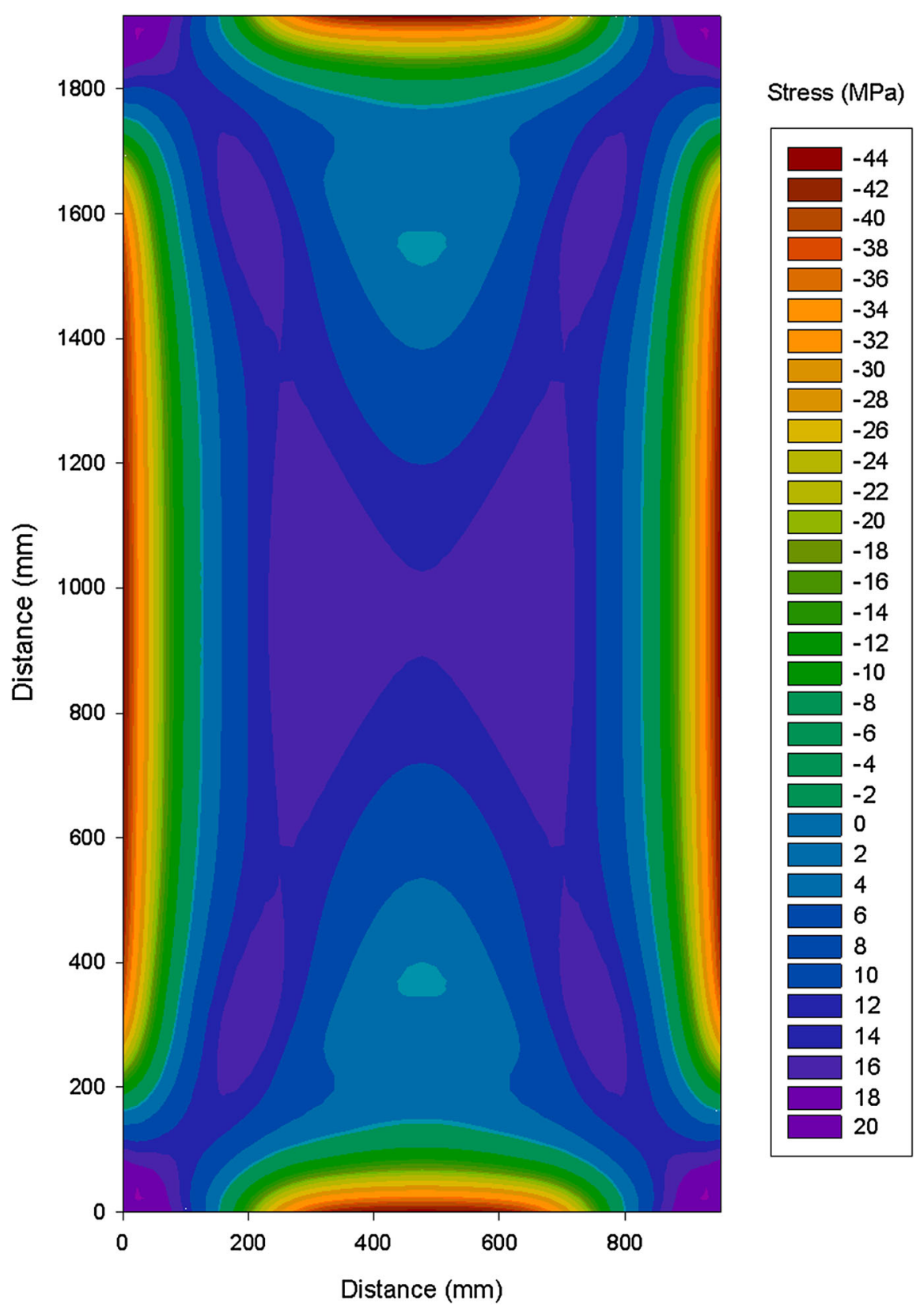

authors note that glass spalled away from the fracture mirror in proximity to the fracture origin and at another area indicated by green arrows. The authors are do not know the cause of the spalling or its significance, if any, at this point. The authors have one other observation from Fig. 14. Just to the left of the fracture mirror, the hole in the frit begins. The glass edge along the hole is much smoother that the glass edge under the frit.
Figure 15 shows an enlarged view of the fracture mirror in this specimen. In this view, the glass is on top. It shows penetration of the ceramic enamel frit into the glass surface at several locations. Note that the view in Fig. 15 is rotated approximately $180^{\circ}$ from Fig. 14 so that the glass is on top. The spalling is clear without the need of an arrow. But something other than glass, most likely frit, seems to be in the fracture origin 
Table 7 Summary of sample statistics for $\mathrm{P}_{3}$

Fig. 8 Normalized experimental cumulative distributions of 3-s equivalent failure loads, $\mathrm{P}_{3}$

Fig. 9 Cumulative distributions of $\mathrm{P}_{3}$ fitted to experimental data

\begin{tabular}{lllllll}
\hline $\begin{array}{l}\text { Sample } \\
\text { number }\end{array}$ & $\begin{array}{l}\text { Maximum } \\
(\mathrm{kPa})\end{array}$ & $\begin{array}{l}\text { Minimum } \\
(\mathrm{kPa})\end{array}$ & $\begin{array}{l}\text { Average } \\
(\mathrm{kPa})\end{array}$ & $\begin{array}{l}\text { Standard } \\
\text { deviation } \\
(\mathrm{kPa})\end{array}$ & $\begin{array}{l}\text { Coefficient of } \\
\text { variation }(\%)\end{array}$ & $\begin{array}{l}\text { Percent } \\
\text { reduction } \\
(\%)\end{array}$ \\
\hline 1 & 25.8 & 12.5 & 20.3 & 2.9 & 14.2 & N/A \\
2 & 15.8 & 12.0 & 14.0 & 1.1 & 8.1 & 31 \\
3 & 15.0 & 11.7 & 13.6 & 0.8 & 5.9 & 33 \\
4 & 15.3 & 11.6 & 13.2 & 0.9 & 6.6 & 35 \\
5 & 11.7 & 8.8 & 10.5 & 0.8 & 7.6 & 48.3 \\
\hline
\end{tabular}
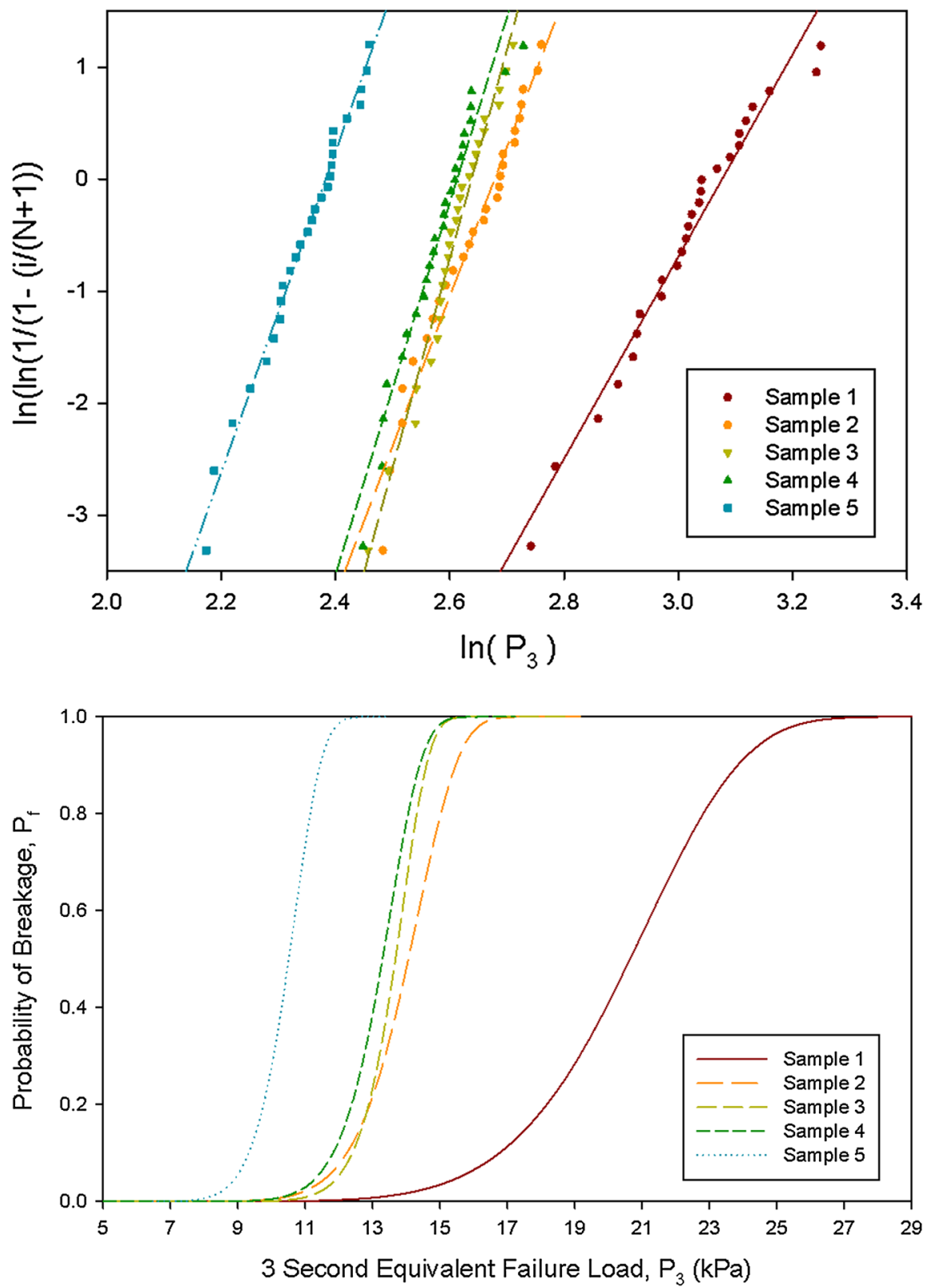
Table 8 Surface flaw (Weibull) parameters for the cumulative distribution functions

\begin{tabular}{lcl}
\hline Sample number & $\mathrm{m}$ & $\begin{array}{l}\mathrm{k}\left\{\left[\text { meter }^{(2 \mathrm{~m}-2)}\right]\right. \\
\left.\left[\text { Newton }^{(-\mathrm{m})}\right]\right\}\end{array}$ \\
\hline 1 & 6.60 & $9.49\left(10^{-30}\right)$ \\
2 & 8.40 & $4.1\left(10^{-35}\right)$ \\
3 & 12.0 & $8.75\left(10^{-49}\right)$ \\
4 & 9.40 & $1.87\left(10^{-38}\right)$ \\
5 & 6.6 & $2.53\left(10^{-26}\right)$ \\
\hline
\end{tabular}

Figure 16 shows the same fracture origin at even greater magnification. The authors note both the rough surface of the glass under the ceramic enamel frit along with the possible penetration of frit into the glass at the center of the fracture origin.

Figure 17 presents the fracture mirror on Specimen 5 from Sample 1, the sample with no frit, for reference. The authors note that the glass edge in proximity to the fracture origin in Fig. 17 is much smoother than glass edges under the frit. The authors believe the roughness of the glass under the frit indicates that that damage occurs to the glass surface during the heating and fusing of the frit to the glass.

When comparing the glass surface at the fracture origin in Fig. 17 to that in Fig. 15, the glass surface appears to be significantly smoother and contains fewer flaws. On the basis of these micrographs, the authors hypothesize that the ceramic enamel frit damages the glass sur-

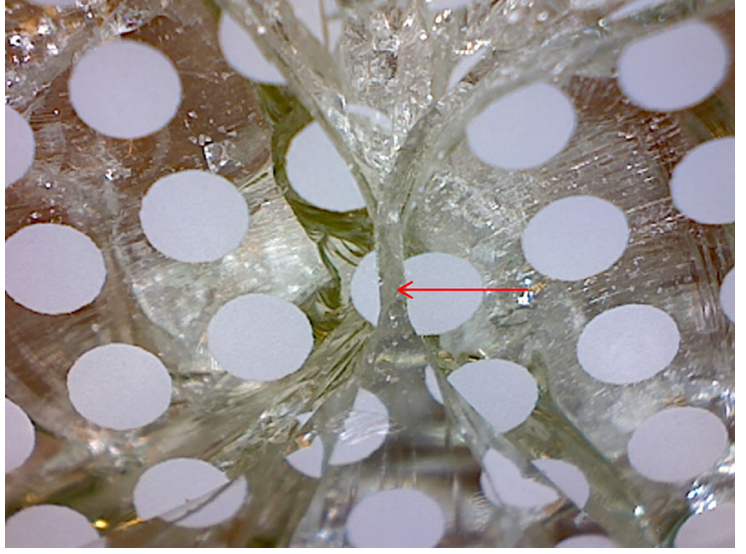

Fig. 11 Fracture origin location for Specimen 2 from Sample 2

Table 9 Values of $\mathrm{P}_{3}$ at the level $\mathrm{P}_{\mathrm{f}}=0.008$

\begin{tabular}{lll}
\hline $\begin{array}{l}\text { Sample } \\
\text { number }\end{array}$ & $\begin{array}{l}\mathrm{P}_{3} \text { for } \\
\mathrm{P}_{\mathrm{f}}=0.008\end{array}$ & $\begin{array}{l}\text { Percent } \\
\text { reduction }\end{array}$ \\
\hline 1 & 13.0 & N/A \\
2 & 10.3 & 20.8 \\
3 & 10.9 & 16.2 \\
4 & 10.2 & 21.5 \\
5 & 8.09 & 37.8 \\
\hline
\end{tabular}

face as it fuses to it during the heat treatment process. The authors will study many more micrographs of fracture origins from these tests as well as from four point bending tests performed previously (Natividad et al. in
Fig. 10 Enlarged view of $\mathrm{P}_{3}$ cumulative distributions for $\mathrm{P}_{\mathrm{f}} \leq 0.01$

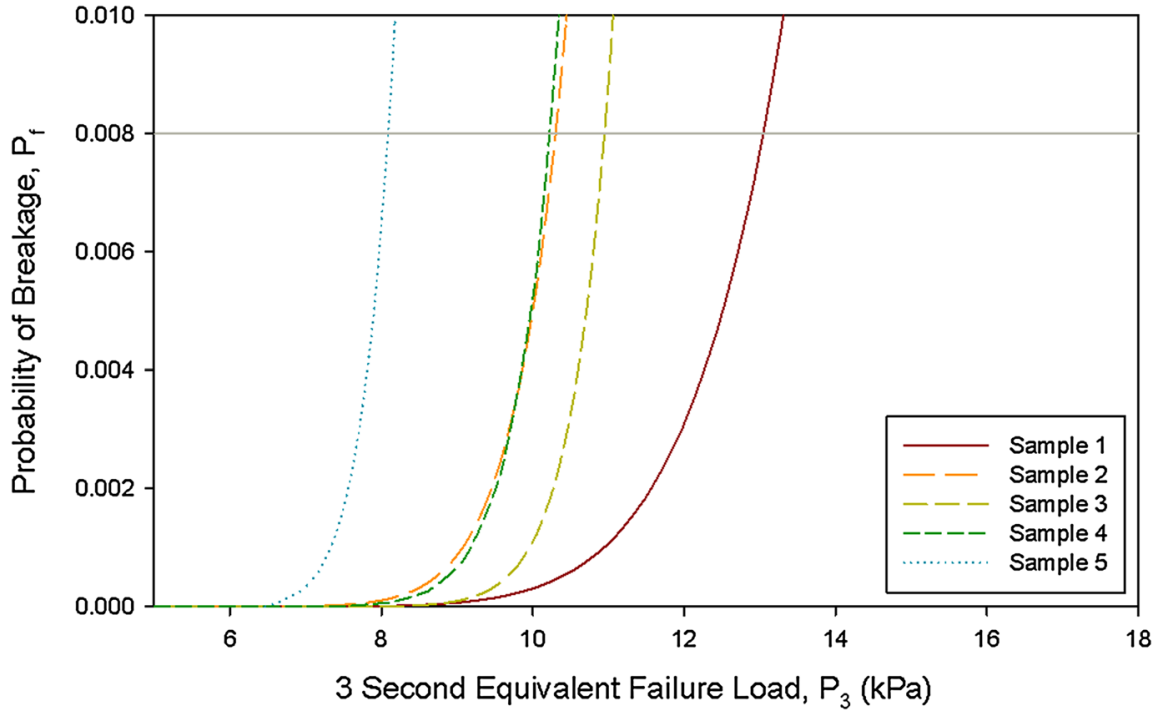




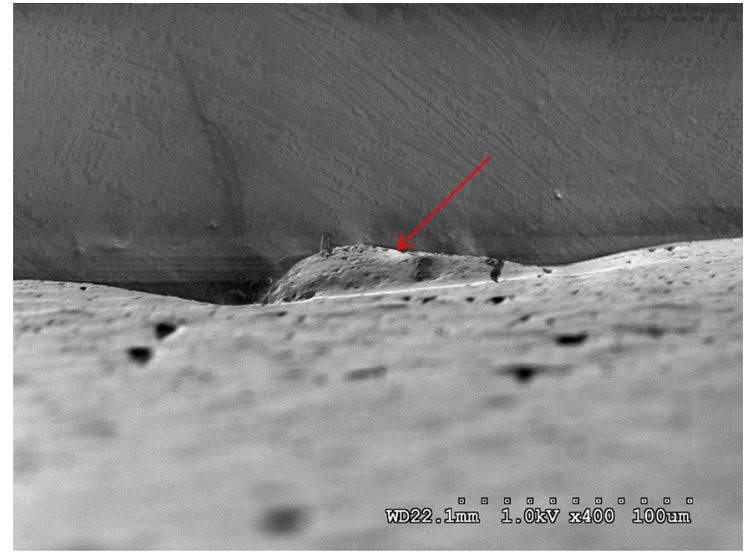

Fig. 12 Micrograph of fracture origin for Specimen 2 from Sample 2

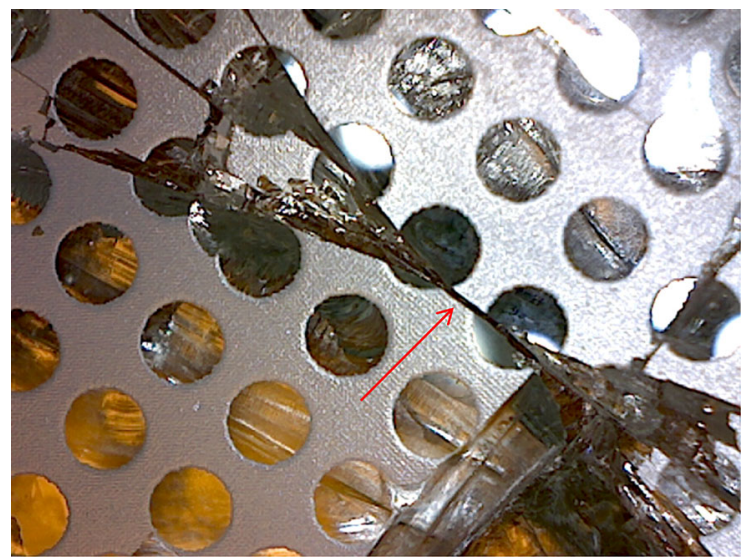

Fig. 13 Fracture origin for Specimen 5 from Sample 4

review). They plan to use elemental analyses to verify that the frit has penetrated the glass surface.

\section{Discussion}

Natividad et al. (in review) reports results from four point bending tests of heat strengthened and fully tempered glass specimens. Their results indicated that a black full coverage ceramic enamel frit reduced the mean load resistance of new heat strengthened glass nearly $60 \%$ from the mean load resistance of clear heat strengthened glass. The reduction in load resistance at the level of $\mathrm{P}_{\mathrm{f}}=0.008$, the load resistance associated with the black full coverage ceramic enamel frit

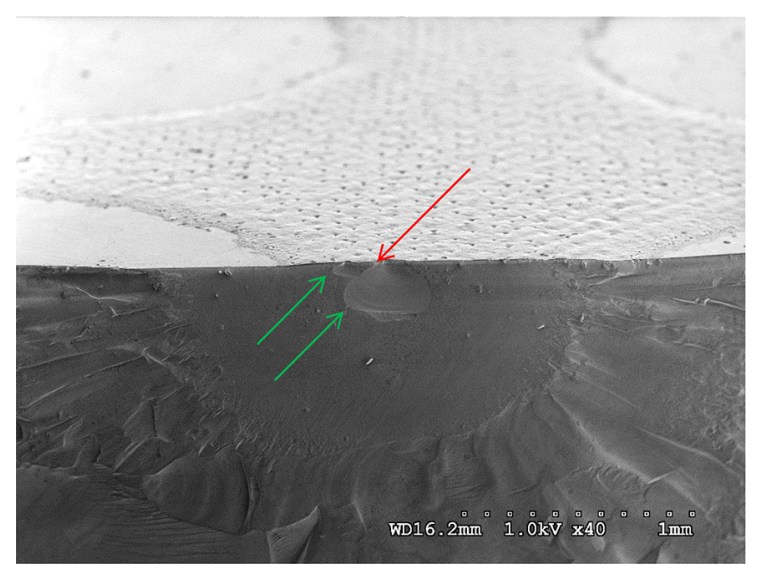

Fig. 14 Fracture mirror for Specimen 5 from Sample 4

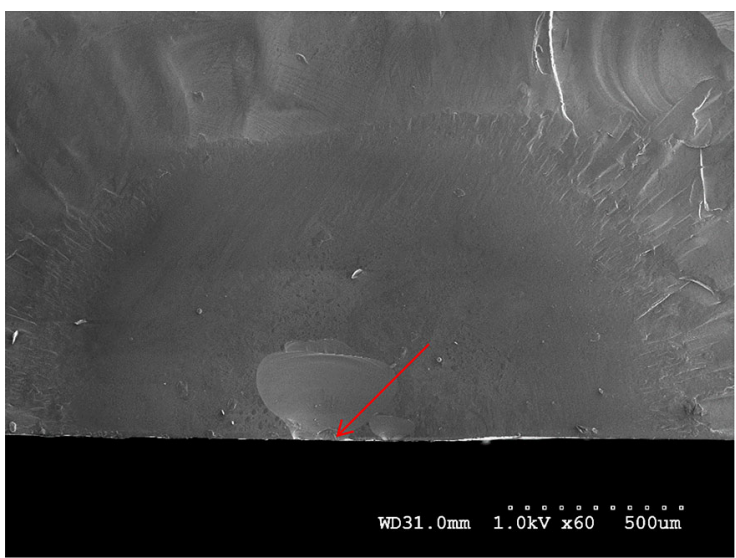

Fig. 15 Enlarged view of fracture mirror for Specimen 5 from Sample 4

was approximately $40 \%$. In the full scale tests reported herein, the reduction in mean load resistance for the full coverage frit was approximately $48 \%$ and at the level of $\mathrm{P}_{\mathrm{f}}=0.008$, the reduction was approximately $37 \%$. These are comparable. The slight differences might be attributable to the different test methods or the different frits. The observation that the frit significantly reduces the load resistance of the glass remains valid.

The European norm prEN 13474 (2012) gives a characteristic strength value for heat strengthened glass with ceramic frit as $45 \mathrm{MPa}$. The mean values of maximum principal tensile stress at the fracture origin at failure for Samples 2, 3, and 4, samples with varying amounts of frit coverage, were all larger than $45 \mathrm{MPa}$. In fact, for the 80 specimens tested in Samples 2, 3, and 


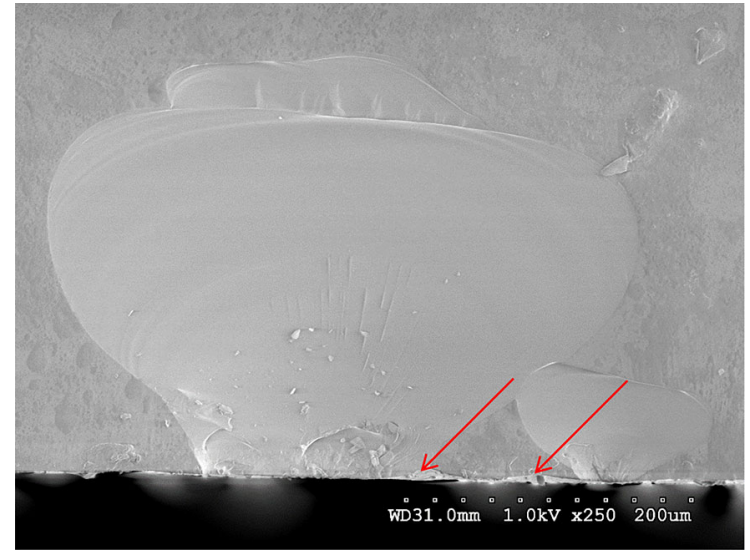

Fig. 16 Fracture origin from Specimen 5 from Sample 4 in Fig. 14

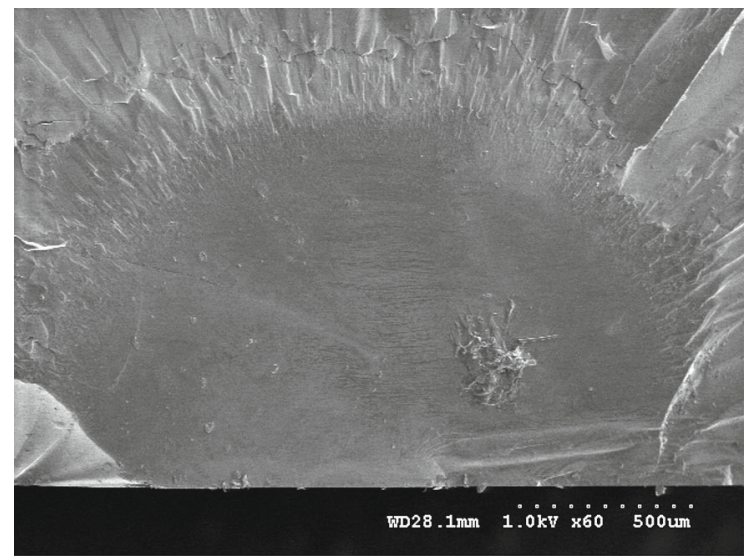

Fig. 17 Fracture mirror from Specimen 5 from Sample 1

4, the maximum principal tensile stress at the fracture origin fell below this value in only 3 specimens. On the other hand, the mean value of maximum principal tensile stress at the fracture origin at failure for Sample 5 is much less than $45 \mathrm{MPa}$. Every specimen in Sample 5 fractured at a value of maximum principal tensile stress at the fracture origin significantly below this value.

\section{Conclusions}

These tests indicate that application ceramic frit significantly reduces the strength of new heat treated glass. They also indicate that frit patterns with less than full coverage lead to smaller strength reductions than does a full coverage application. European norms (EN 1863-
2 2004; prEN 13474 2012) account for this reduction The values of maximum principal tensile stress at the fracture origin at failure from these tests indicate that the characteristic strength value of $45 \mathrm{MPa}$ in European norms adequately represents heat strengthened glass with frit patterns. On the other hand, the value of $45 \mathrm{MPa}$ may be too high for full coverage frit.

In the US, design standards do not recognize a reduction in glass strength resulting from an application of frit. These tests indicate that US standards should be revised to reflect the fact that the application of ceramic frit reduces glass strength. ASTM E1300 (2012c) bases its load resistance values on weathered glass strength. Further research must be conducted to determine the degree of strength reduction associated with ceramic frit on weathered glass. The authors feel, even in the absence of data associated with weathered glass with ceramic enamel frit, that ASTM E1300 (2012c) should mandate a strength reduction for ceramic frit.

Finally, micrographs indicate that during the fusing process, the ceramic frit penetrates the glass surface as would be expected. The authors felt the damage to the glass surface caused be the frit is a significant factor in the strength reduction.

Acknowledgments The authors wish to thank Viracon for providing the test specimens and for making critical comments on this article. They further applaud Viracon for taking a proactive stance in what is becoming a very contentious issue in U.S. glass design.

\section{References}

Abiassi, J.J.: The Strength of Weathered Window Glass Using Surface Characteristics. NTIS Accession No. PB82172735. Institute for Disaster Research, Texas Tech University, Lubbock (1981)

ASTM E998: Standard Test Method for Structural Performance of Glass in Windows, Curtain Walls, and Doors Under the Influence of Uniform Static Loads by Nondestructive Method. ASTM, West Conshohocken (2012a)

ASTM C1048: Standard Specification for Heat-Strengthened and Fully Tempered Flat Glass. ASTM, West Conshohocken (2012b)

ASTM E1300: Standard Practice for Determining the Load Resistance of Glass in Buildings. ASTM, West Conshohocken (2012c)

Brown, W.G.: A Practicable Formulation for the Strength of Glass and Its Special Application to Large plates. Pub. No. NRC 14372. National Research Council of Canada, Ottawa (1974) 
Beason, W.L.: A Failure Prediction Model for Window Glass. NTIS Accession No. PB81-148421. Institute for Disaster Research, Texas Tech University, Lubbock (1980)

EN 1863-2: Glass in Building-Heat Strengthened Soda Lime Silicate Glass-Part 2: Evaluation of Conformity/Product Standard. BSI, Brussels (2004)

Justel, A., Pena, D., Zamar, R.: A multivariate KolmogorvSmirnov test of goodness of fit. Stat. Probab. Lett. 35(3), 251-259 (1997)

Kanabolo, D.C., Norville, H.S.: The Strength of New Window Glass Plates Using Surface Characteristics. NTIS Accession No. PB86-140100. Glass Research and Testing Laboratory, Texas Tech University, Lubbock (1984)

Krall, W.R., Siskos, W.R., Spindler, R.G., Stewart, R.A.: The Behavior of Float Glass Under Uniform Windloading. In: Preprints of Fourth U.S. National Conference on Wind Engineering Research, pp. 155-159. University of Washington, Seattle (1981)

Krampe, P.: Zur Festigkeit emaillierter Gläser. PhD-thesis, Technische Universität, Dresden (2013)

Krohn, M., Hellmann, J., Shelleman, D., Pantano, C., Sakoske, G.: Effect of enameling on the strength and dynamic fatigue of soda-lime-silica float glass. J. Am. Ceram. Soc. 85(10), 2507-2514(2002)
Natividad, K., Morse, S.M., Norville, H.S.: Tests of heat treated glass with ceramic frit. J. Arch. Eng. ASCE (in review)

Norville, H.S., Minor, J.E.: The strength of weathered window glass. Bull. Am. Ceram. Soc. 64(11), 1467-1470 (1985)

Pettitt, A.N.: A two-sample Anderson-Darling rank statistic. Biometrika 63(1), 161-168 (1976)

prEN 13474: Glass in Building-Determination of the Strength of Glass Panes by Calculation and Testing. BSI, Brussels (2012)

Schmidt, A.: Silkscreen glass: energy performance and esthetics. Constr. Can. 49, 4 (2007)

Vallabhan, C.V.G., Wang, B.Y.-T.: Nonlinear Analysis of Rectangular Glass Plates by Finite Difference Method. NTIS Accession No. PB82-172552. Institute for Disaster Research, Texas Tech University, Lubbock (1981)

Weibull, W.: A Statistical Theory of the Strength of Materials. Handlinger NR 151. Royal Technical University, Stockholm (1939) 